\title{
Multimorbidity disease clusters in Aboriginal and non-Aboriginal Caucasian populations in Canada
}

\section{J. P. Kuwornu, MSc (1); L. M. Lix, PhD (1); S. Shooshtari, PhD $(1,2)$}

This article has been peer reviewed.

\begin{abstract}
Introduction: Patterns of multimorbidity, the co-occurrence of two or more chronic diseases, may not be constant across populations. Our study objectives were to compare prevalence estimates of multimorbidity in the Aboriginal population in Canada and a matched non-Aboriginal Caucasian population and identify the chronic diseases that cluster in these groups.
\end{abstract}

Methods: We used data from the 2005 Canadian Community Health Survey (CCHS) to identify adult ( $\geq 18$ years) respondents who self-identified as Aboriginal or nonAboriginal Caucasian origin and reported having 2 or more of the 15 most prevalent chronic conditions measured in the CCHS. Aboriginal respondents who met these criteria were matched on sex and age to non-Aboriginal Caucasian respondents. Analyses were stratified by age (18-54 years and $\geq 55$ years). Prevalence was estimated using survey weights. Latent class analysis (LCA) was used to identify disease clusters.

Results: A total of 1642 Aboriginal respondents were matched to the same number of non-Aboriginal Caucasian respondents. Overall, 38.9\% (95\% CI: 36.5\%-41.3\%) of Aboriginal respondents had two or more chronic conditions compared to $30.7 \%$ (95\% CI: $28.9 \%-32.6 \%$ ) of non-Aboriginal respondents. Comparisons of LCA results revealed that three or four clusters provided the best fit to the data. There were similarities in the diseases that tended to co-occur amongst older groups in both populations, but differences existed between the populations amongst the younger groups.

Conclusion: We found a small group of younger Aboriginal respondents who had complex co-occurring chronic diseases; these individuals may especially benefit from disease management programs.

Keywords: Aboriginal, chronic disease, latent class analysis, prevalence

\section{Introduction}

Multimorbidity, the co-occurrence of two or more chronic diseases where one is not necessarily more central than the others, ${ }^{1}$ is associated with increased health care utilization and decreased quality of life. ${ }^{2-4}$ Unlike comorbidity, where there is an index (i.e. primary) condition of interest, multimorbidity has no index condition. Prevalence of multimorbidity is known to vary with risk factors such as gender, ${ }^{1}$ age, ${ }^{2}$ socioeconomic status, ${ }^{5,6}$ and ethnicity. ${ }^{7}$ Countries with socioculturally diverse populations may therefore face unique challenges in providing care for multimorbidity. ${ }^{8}$

Identifying co-occurring chronic diseases can contribute to improved care management strategies for multimorbid patients in risk groups. While some studies have taken the approach of reporting on the prevalence of specific combinations of diseases, a number of studies have used clustering techniques, such as cluster analysis, to examine patterns of multimorbidity. ${ }^{9-13}$ Latent class analysis (LCA), a technique that can be used to identify groups of related diseases (i.e. latent classes) has, to the best of our knowledge, not been applied to examine patterns of multimorbidity in different populations, although it has been used in other studies of chronic diseases. ${ }^{14}$ LCA is recommended over conventional clustering methods because it uses probability-based classification methods and provides various diagnostic tests that can be useful in determining the optimal number of classes. ${ }^{15}$

Few studies have explored the prevalence of co-occurring chronic diseases in different risk groups within the population. Schafer et al. ${ }^{9}$ compared chronic disease clusters in senior male and female German populations and found three disease clusters in both groups but differences in the chronic disease cluster compositions. For example, women in one cluster showed relatively more pre-terminal conditions such as chronic ischemic heart disease and renal insufficiency.

Prevalence of chronic diseases has been increasing in the Aboriginal population (which comprises First Nations, Métis and Inuit peoples). ${ }^{16}$ The potential for increasing rates of multimorbidity is of concern. However, to date no studies have examined prevalence rates in this population, or whether the chronic diseases that tend to cluster differ between Aboriginal and

\section{Author references:}

1. Department of Community Health Sciences, Faculty of Medicine, University of Manitoba, Winnipeg, Manitoba, Canada 2. Department of Family Social Sciences, University of Manitoba, Winnipeg, Manitoba, Canada

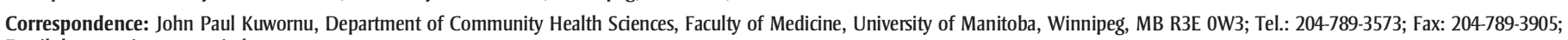
Email: kuwornuj@myumanitoba.ca 
non-Aboriginal populations. For example, diabetes prevalence, which is increasing more rapidly in Aboriginal than in nonAboriginal populations in Canada, ${ }^{17}$ might result in clusters of associated co-occurring conditions such as renal disease and cardiovascular disease.

Our objectives were (1) to estimate prevalence of multimorbidity among the Aboriginal population in Canada and compare this prevalence to the estimate for a matched non-Aboriginal Caucasian population, and (2) to compare the clusters of chronic diseases that co-occur in these two groups across two age groups.

\section{Methods}

\section{Study population and variables}

Study data were from the 2005 Canadian Community Health Survey (CCHS) Cycle 3.1, conducted by Statistics Canada. ${ }^{18}$ The CCHS is a cross-sectional, populationbased survey intended to provide information on health determinants, health status and health care system utilization for 122 health regions in Canada. The survey was conducted every 2 years from 2001 to 2005 and annually since 2007 . Cycle 3.1 was selected for this study because, when compared to Cycle 4.1, it has a sufficiently large number of Aboriginal respondents to enable use of LCA techniques in the analyses for younger and older age groups. The target population for the CCHS Cycle 3.1 was individuals aged 12 years or older living in private dwellings in Canada's provinces and territories. The CCHS adopts a multistage, stratified cluster design to select eligible individuals and their households ( $n=132$ 221; response rate $=92.9 \%$ ). Excluded from the CCHS are institutionalized individuals, residents of First Nations reserves and full-time members of the Canadian Forces.

The study inclusion criteria were (1) 18 years of age or older, to focus on the adult population, (2) self-identification as either an Aboriginal person or a non-Aboriginal Caucasian, and (3) reporting at least 2 of the 15 most prevalent chronic diseases in the CCHS Cycle 3.1. We identified the Aboriginal population based on the derived variable provided in CCHS Cycle
3.1, which combines information from two variations of one question. The question used prior to June 2005 has the following preamble: "People living in Canada come from many different cultural and racial backgrounds." We identified respondents as Aboriginal if they responded "yes" to the question that followed: "Are you Aboriginal (North American Indian, Métis, Inuit)?” As of June 2005, the question used to identify Aboriginal respondents was changed to "Are you an Aboriginal person, that is, North American Indian, Métis or Inuit?” The non-Aboriginal Caucasian population was identified based on a similarly constructed derived variable provided in CCHS Cycle 3.1. ${ }^{19}$

We undertook a one-to-one match between the Aboriginal respondents who met the study inclusion criteria and their non-Aboriginal Caucasian counterparts using sex and age (in 5-year bands) as the matching criteria. Each Aboriginal respondent was successfully matched to a non-Aboriginal Caucasian respondent. In cases where there were more than one qualified non-Aboriginal Caucasian respondents for a match to an Aboriginal respondent, the matched pair was selected at random. One-to-many matching would be advantageous if there was a substantially lower prevalence of one or more chronic conditions in the non-Aboriginal Caucasian population in order to ensure adequate precision of these prevalence estimates. However, there were no substantial differences in prevalence between the two groups in our study. Although discarding individuals in the matching process to achieve a one-to-one match will result in a smaller sample size, this does not necessarily lead to increases in the sampling variance of estimates. Matching generally improves balance in the covariate distribution, which can decrease the variance of estimators. ${ }^{20}$ Matching was undertaken to ensure comparability of the groups on 2 demographic variables, which are known to be associated with chronic disease prevalence (age and sex). The respondents were subsequently stratified into a younger age group (i.e. 18 to 54 years) and older age group (i.e. 55 years or older). The purpose of this stratification was to explore the differences, if any, in disease clustering between younger and older age groups in each population.

Only those health conditions that had at least $5 \%$ prevalence in both the Aboriginal and matched non-Aboriginal Caucasian populations, based on weighted prevalence estimates, were selected for investigating chronic disease clusters. The CCHS questions about chronic disease are prefaced with the following preamble "Now I'd like to ask about certain chronic health conditions which you may have. We are interested in 'long-term conditions' which are expected to last or have already lasted 6 months or more and that have been diagnosed by a health professional." Respondents were then asked by the interviewer if they had the identified disease(s). ${ }^{19}$ We coded the responses relating to each disease as yes or no. All other responses (i.e. not sure, no response) were treated as missing values. The 15 chronic diseases included in this study were asthma, arthritis or rheumatism, anxiety or mental disorders, back problems, bowel disease, cataracts, diabetes, emphysema or bronchitis or chronic obstructive pulmonary disease (COPD), food allergies, heart disease, high blood pressure, incontinence, migraine, thyroid conditions, and ulcers. Multimorbidity was defined as the presence of two or more of these conditions.

\section{Statistical analysis}

Aboriginal and matched non-Aboriginal Caucasian respondents were described on age, sex and prevalence of each of the 15 above-mentioned chronic diseases. Multimorbidity prevalence was estimated along with 95\% confidence intervals (CIs). For the Aboriginal population, the numerator of the prevalence estimate was the number of Aboriginal respondents who met the study inclusion criteria and the denominator was the total number of Aboriginal respondents aged 18 years or older. For the non-Aboriginal Caucasian population, the numerator was the number of matched non-Aboriginal Caucasian respondents who met the study inclusion criteria and the denominator was the total number of non-Aboriginal Caucasian respondents aged 18 years or older who 
met the matching criteria. Prevalence estimates were expressed as percentages.

LCA was applied separately to the data for the younger and older Aboriginal and matched non-Aboriginal Caucasian respondents. LCA assumes that each individual in the study belongs to one of a set of mutually exclusive and exhaustive classes. ${ }^{21}$ We calculated class membership probabilities, which are estimates of the proportion of respondents belonging to each latent class, and item response probabilities (presence of a disease) conditional on class membership, which are estimates of the prevalence of the chronic diseases for each of the latent classes. ${ }^{21}$ These item response probabilities are used to characterize latent classes in a similar way to the use of factor loadings to characterize factors in factor analysis. We interpreted item response probabilities of 0.4 or greater as indicative of an association between the item and the corresponding latent class, which is consistent with previous factor analysis studies about multimorbidity patterns that have used factor loading cut-offs of $0.4 .^{22}$

We fitted models to the data using between two and seven classes, to determine the optimal number of classes. The Akaike Information Criterion (AIC) ${ }^{23}$ and the Bayesian-Schwarz Information Criterion (BIC), ${ }^{24}$ which are penalized measures of the likelihood function, were used to guide the selection of the final number of classes (Figure 1). ${ }^{25}$ A smaller AIC and BIC for a particular model suggests that it is preferable on the basis of the trade-off between fit and parsimony.

Measurement invariance was tested between the Aboriginal and matched non-Aboriginal respondents. This was done by first fitting a model in which the parameters of the item responses were freely estimated for both groups. A second model was then fitted to the data in which parameters were constrained to be equal across groups. The difference in the likelihood ratio statistics for the two nested models, $G^{2}$, asymptotically follows a $\chi^{2}$ distribution. The degrees of freedom $(d f)$ for this difference statistic is equal to the difference in degrees of freedom between the two nested models. If the null hypothesis of measurement invariance is
FIGURE 1

Akaike Information Criteria and Bayesian-Schwarz Information Criteria values for latent class analysis models in Aboriginal and matched non-Aboriginal Caucasian CCHS respondents

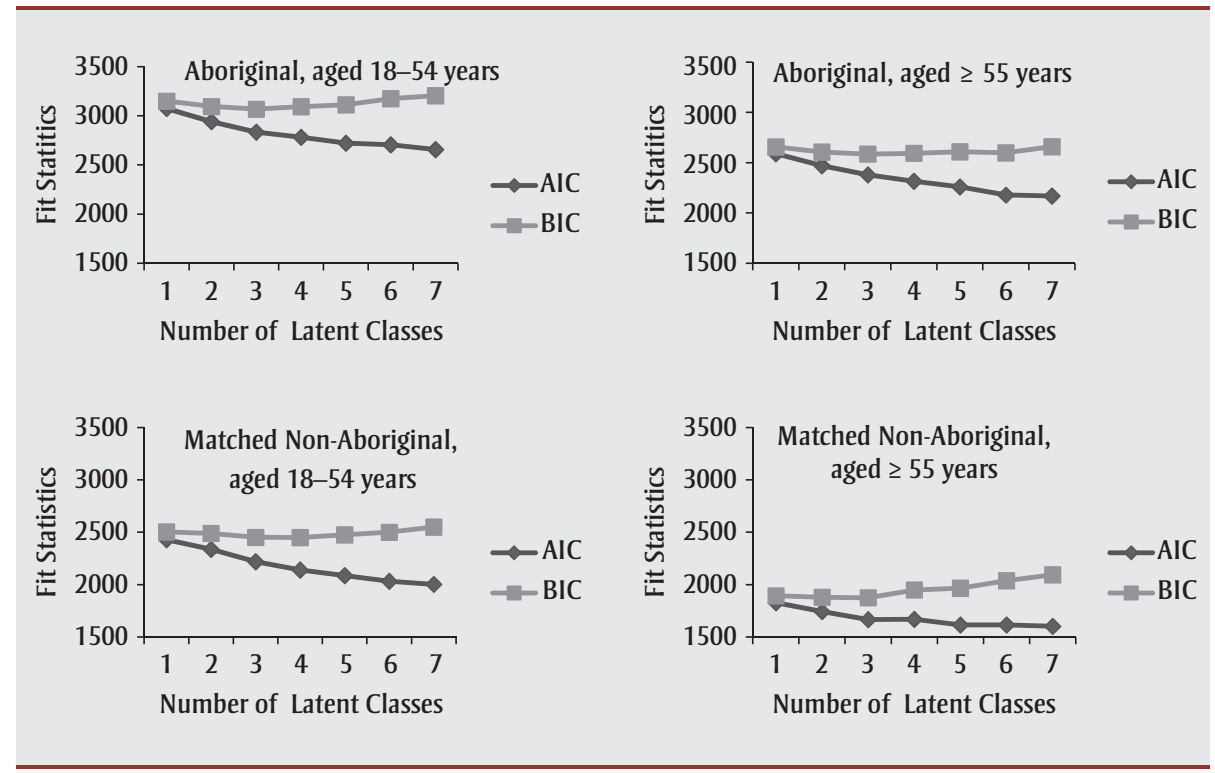

Abbreviations: AIC, Akaike Information Criteria; BIC, Bayesian-Schwarz Information Criteria; CCHS, Canadian Community Health Survey.

retained, then the identified classes are assumed to be the same for both groups; if the null hypothesis is rejected, then it is recommended that separate classes be estimated for the two groups. ${ }^{21}$ The tests were conducted separately for the younger and older populations. In each case, only the optimal model(s) based on the fit statistics and model interpretability results were selected for testing measurement invariance.

The analysis was implemented using PROC LCA version 1.3.0 ${ }^{26}$ in SAS version 9.3. ${ }^{27}$ All analyses were conducted using full sample weights. Permission to access the data was granted by Statistics Canada.

\section{Results}

A total of 1642 Aboriginal respondents (weighted $n=198$ 955) who met the study inclusion criteria were matched to an equal number of non-Aboriginal Caucasian respondents (weighted $\mathrm{n}=169$ 149). Table 1 shows the age-stratified Aboriginal and matched non-Aboriginal Caucasian cohorts. The mean age (standard deviation [SD]) of the younger (18-54 years) Aboriginal cohort was 37.4 (17.8) years, and $39.4 \%$ were male. The mean (SD) age of the older ( $\geq 55$ years) Aboriginal cohort was 64.8 (10.8) years, and $41.9 \%$ of them were male. The age and sex distribution of the non-Aboriginal study cohort were similar to those of the Aboriginal study cohort because of the matching process.

In both the younger and older age groups, the mean number of chronic conditions was higher for the Aboriginal than for the non-Aboriginal respondents. Back problems were the most prevalent condition in both the younger Aboriginal (55.8\%) and non-Aboriginal study cohorts (50.8\%). For the older age group, arthritis/rheumatism was the most prevalent condition in both the Aboriginal (63.4\%) and nonAboriginal (64.5\%) study cohorts.

Overall, multimorbidity prevalence was $38.9 \%(95 \%$ CI: $36.5 \%-41.3 \%)$ in the Aboriginal population compared with $30.7 \%$ (95\% CI: $28.9 \%-32.6 \%)$ in the non-Aboriginal population. The prevalence of multimorbidity was higher in the older Aboriginal group (64.0\%; $95 \% \mathrm{CI}$ : $58.7 \%-69.2 \%)$ than the non-Aboriginal group (58.3\%; 95\% CI: $53.7 \%-63.0 \%)$. Similarly, multimorbidity prevalence was higher in the younger Aboriginal (33.7\%; $95 \%$ CI: $31.1 \%-36.2 \%)$ than the non- 
TABLE 1

Demographic and chronic disease characteristics of Aboriginal and matched non-Aboriginal Caucasian CCHS respondents by age groups

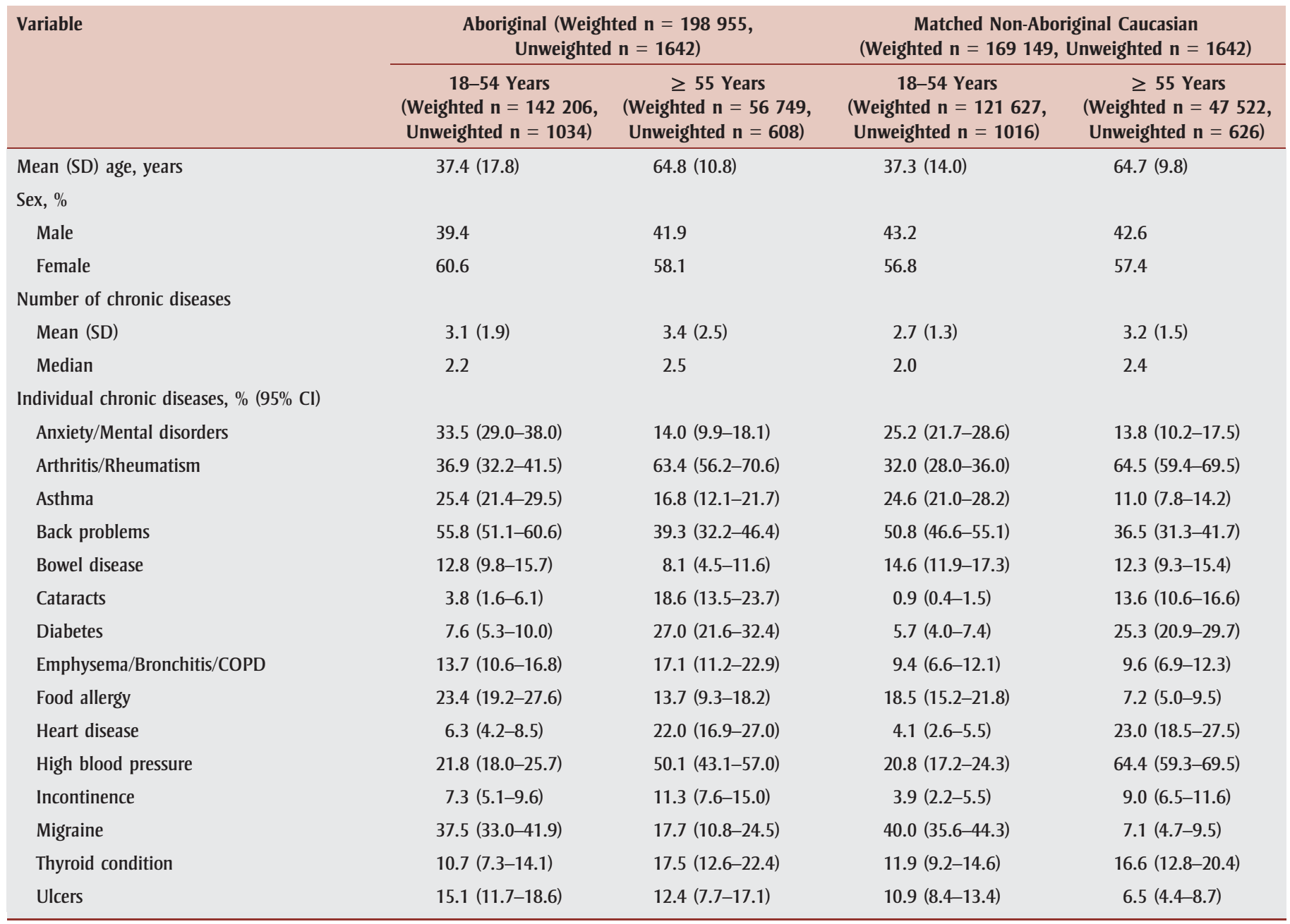

Abbreviations: CCHS, Canadian Community Health Survey; COPD, chronic obstructive pulmonary disease.

Note: Small differences in the sex and age distribution between the Aboriginal and matched non-Aboriginal Caucasian respondents were as a result of applying survey weights.

Aboriginal groups $(25.7 \%$; $95 \%$ CI: Aboriginal and non-Aboriginal respondents $23.6 \%-27.7 \%$ ) (data not shown).

The LCA model fit results are summarized in Figure 1. While AIC values decreased with an increase in the number of latent classes in both populations and for the two age groups, this was not the case for the BIC, which began to increase (indicating poorer fit) after three classes in both age groups in the Aboriginal population, and in the older age group of the non-Aboriginal population. The BIC values began to increase after four classes in the younger non-Aboriginal group. Consequently, we chose to compare the three-class and fourclass model solutions for both groups.

Among the younger respondents, the test of measurement invariance between resulted in $G^{2}=192.6(d f=45)$ for the 3class model $(p<.0001)$ and $G^{2}=224.0(d f$ $=60)$ for the 4 -class model $(p<.0001)$. For the older respondents, the test for measurement invariance between Aboriginals and non-Aboriginals resulted in $G^{2}=189.6(d f$ $=45)$ for the 3 -class model $(p<.0001)$ and $\mathrm{G}^{2}=182.3(d f=60)$ for the 4-class model $(p<.0001)$. These results suggest that measurement non-invariance exists in the data, and therefore LCA model parameters were estimated separately for Aboriginal and non-Aboriginal respondents in each age group.

\section{Characteristics of the three-class model}

Table 2 shows the class membership percentages and item response probabilities for three classes. The first latent class constituted less than $12 \%$ of younger respondents in both populations $5.8 \%$ for Aboriginal and $11.9 \%$ for non-Aboriginal respondents). The second class accounted for almost one-fifth (18.3\%) of younger Aboriginal respondents. In the younger matched non-Aboriginal group, the second class accounted for more than one-quarter (27.6\%) of respondents. More than half $(52.7 \%)$ of the older Aboriginal respondents belonged to the second class compared to only $39.8 \%$ of the older nonAboriginal Caucasian respondents.

\section{Younger group}

For the three-class model in the younger Aboriginal population, the first class had high item-response probabilities on eight of the chronic diseases, while the second 
TABLE 2

Item response probabilities for three classes of chronic diseases in Aboriginal and matched non-Aboriginal Caucasian CCHS respondents by age groups

\begin{tabular}{|c|c|c|c|c|c|c|}
\hline \multirow[t]{3}{*}{ Chronic disease } & \multicolumn{6}{|c|}{ 18-54 Years } \\
\hline & \multicolumn{3}{|c|}{ Aboriginal } & \multicolumn{3}{|c|}{$\begin{array}{c}\text { Matched Non-Aboriginal } \\
\text { Caucasian }\end{array}$} \\
\hline & $\begin{array}{l}\text { Class } 1 \\
(5.8 \%)\end{array}$ & $\begin{array}{l}\text { Class } 2 \\
(18.3 \%)\end{array}$ & $\begin{array}{l}\text { Class } 3 \\
(75.9 \%)\end{array}$ & $\begin{array}{l}\text { Class } 1 \\
(11.9 \%)\end{array}$ & $\begin{array}{l}\text { Class } 2 \\
(27.6 \%)\end{array}$ & $\begin{array}{l}\text { Class } 3 \\
(60.5 \%)\end{array}$ \\
\hline Anxiety/Mental disorders & 0.678 & 0.189 & 0.344 & 0.230 & 0.168 & 0.294 \\
\hline Arthritis/Rheumatism & 0.632 & 0.312 & 0.362 & 0.158 & 0.292 & 0.364 \\
\hline Asthma & 0.510 & 0.063 & 0.281 & 1.000 & 0.183 & 0.127 \\
\hline Back problems & 0.600 & 0.376 & 0.599 & 0.267 & 0.356 & 0.626 \\
\hline Bowel disease & 0.189 & 0.080 & 0.135 & 0.144 & 0.062 & 0.184 \\
\hline Cataract & 0.256 & 0.000 & 0.031 & 0.003 & 0.015 & 0.008 \\
\hline Diabetes & 0.244 & 0.158 & 0.045 & 0.023 & 0.135 & 0.028 \\
\hline Emphysema/Bronchitis/COPD & 0.541 & 0.008 & 0.138 & 0.203 & 0.058 & 0.089 \\
\hline Food allergy & 0.181 & 0.167 & 0.254 & 0.356 & 0.096 & 0.192 \\
\hline Heart disease & 0.436 & 0.080 & 0.031 & 0.000 & 0.128 & 0.009 \\
\hline High blood pressure & 0.645 & 0.989 & 0.000 & 0.000 & 0.751 & 0.000 \\
\hline Incontinence & 0.268 & 0.036 & 0.068 & 0.000 & 0.024 & 0.053 \\
\hline Migraine & 0.608 & 0.248 & 0.387 & 0.055 & 0.290 & 0.518 \\
\hline Thyroid condition & 0.116 & 0.070 & 0.115 & 0.050 & 0.110 & 0.137 \\
\hline Ulcers & 0.515 & 0.078 & 0.142 & 0.053 & 0.124 & 0.114 \\
\hline \multirow[t]{3}{*}{ Chronic disease } & \multicolumn{6}{|c|}{$\geq 55$ Years } \\
\hline & \multicolumn{3}{|c|}{ Aboriginal } & \multicolumn{3}{|c|}{$\begin{array}{l}\text { Matched Non-Aboriginal } \\
\text { Caucasian }\end{array}$} \\
\hline & $\begin{array}{l}\text { Class } 1 \\
(14.7 \%)\end{array}$ & $\begin{array}{l}\text { Class } 2 \\
(52.7 \%)\end{array}$ & $\begin{array}{l}\text { Class } 3 \\
(32.6 \%)\end{array}$ & $\begin{array}{l}\text { Class } 1 \\
(31.4 \%)\end{array}$ & $\begin{array}{l}\text { Class 2 } \\
(39.8 \%)\end{array}$ & $\begin{array}{l}\text { Class 3 } \\
(28.8 \%)\end{array}$ \\
\hline Anxiety/Mental disorders & 0.328 & 0.084 & 0.146 & 0.126 & 0.082 & 0.230 \\
\hline Arthritis/Rheumatism & 0.931 & 0.591 & 0.575 & 0.734 & 0.546 & 0.683 \\
\hline Asthma & 0.780 & 0.056 & 0.076 & 0.188 & 0.095 & 0.045 \\
\hline Back problems & 0.608 & 0.233 & 0.555 & 0.310 & 0.212 & 0.636 \\
\hline Bowel disease & 0.190 & 0.025 & 0.122 & 0.225 & 0.000 & 0.183 \\
\hline Cataract & 0.121 & 0.194 & 0.202 & 0.290 & 0.113 & 0.000 \\
\hline Diabetes & 0.398 & 0.401 & 0.000 & 0.256 & 0.434 & 0.000 \\
\hline Emphysema/Bronchitis/COPD & 0.508 & 0.085 & 0.157 & 0.307 & 0.000 & 0.000 \\
\hline Food allergy & 0.156 & 0.102 & 0.186 & 0.103 & 0.022 & 0.109 \\
\hline Heart disease & 0.246 & 0.297 & 0.084 & 0.353 & 0.223 & 0.105 \\
\hline High blood pressure & 0.549 & 0.751 & 0.076 & 0.539 & 0.886 & 0.423 \\
\hline Incontinence & 0.200 & 0.085 & 0.120 & 0.212 & 0.023 & 0.051 \\
\hline Migraine & 0.306 & 0.081 & 0.273 & 0.081 & 0.024 & 0.126 \\
\hline Thyroid condition & 0.284 & 0.155 & 0.160 & 0.144 & 0.088 & 0.297 \\
\hline Ulcers & 0.187 & 0.031 & 0.246 & 0.067 & 0.047 & 0.088 \\
\hline
\end{tabular}

Abbreviations: CCHS, Canadian Community Health Survey; COPD, chronic obstructive pulmonary disease.

Note: Bold values represent diseases with item response probabilities of 0.400 or greater.

class had high item-response probabilities for high blood pressure, and the third class had high item-response probabilities for back problems. Among the younger nonAboriginal respondents, the first and second classes had high item-response probabilities for asthma and high blood pressure, respectively. The third class had high probabilities for both back problems and migraine.

\section{Older group}

For the three-class model in the older Aboriginal population, the first class had high probabilities on five of the chronic diseases, while the second class had high probabilities for arthritis/rheumatism, diabetes and high blood pressure. The third class had high probabilities for arthritis/ rheumatism and back problems. Arthritis/ rheumatism and high blood pressure had the highest item response probabilities in the first class among the older nonAboriginal respondents. The conditions that had high item-response probabilities in the second class of the older Aboriginal respondents were the same for older nonAboriginal respondents (arthritis/rheumatism, diabetes and high blood pressure). The conditions with the highest probabilities in the third class for older nonAboriginal respondents were arthritis/ rheumatism, back problems and high blood pressure. Overall, the 3-class LCA model results reveal that more chronic conditions tended to cluster together in the older age group in both Aboriginal and non-Aboriginal populations than in the younger age groups of both populations.

\section{Characteristics of the four-class model}

\section{Younger group}

The differences observed between the younger Aboriginal and non-Aboriginal age groups in the three-class model persisted in the four-class model (Table 3). In the Aboriginal group, the size of the first latent class remained small (6.0\%) and the same diseases had high item-response probabilities. The second class comprised one-fifth of respondents (21\%) and had a high item-response probability for high blood pressure. The third class, which comprised almost twothirds $(62.4 \%)$ of the respondents, had a high item-response probability for back problems. The fourth class had high itemresponse probabilities for both back problems and ulcers. The first class in the non-Aboriginal respondents was also small (13.1\%) and had a high itemresponse probability for asthma. The second and third classes in these respondents had high blood pressure and migraine as the only conditions with high probabilities, respectively. 
TABLE 3

Item response probabilities for four classes of chronic diseases in Aboriginal and matched non-Aboriginal Caucasian CCHS respondents by age groups

\begin{tabular}{|c|c|c|c|c|c|c|c|c|}
\hline \multirow[t]{3}{*}{ Chronic disease } & \multicolumn{8}{|c|}{$18-54$ Years } \\
\hline & \multicolumn{4}{|c|}{ Aboriginal } & \multicolumn{4}{|c|}{ Matched Non-Aboriginal Caucasian } \\
\hline & $\begin{array}{c}\text { Class } 1 \\
(6.0 \%)\end{array}$ & $\begin{array}{c}\text { Class } 2 \\
(21.0 \%)\end{array}$ & $\begin{array}{l}\text { Class } 3 \\
(62.4 \%)\end{array}$ & $\begin{array}{c}\text { Class } 4 \\
(11.6 \%)\end{array}$ & $\begin{array}{c}\text { Class } 1 \\
(13.1 \%)\end{array}$ & $\begin{array}{c}\text { Class } 2 \\
(20.7 \%)\end{array}$ & $\begin{array}{l}\text { Class } 3 \\
(39.4 \%)\end{array}$ & $\begin{array}{c}\text { Class } 4 \\
(26.8 \%)\end{array}$ \\
\hline Anxiety/Mental disorders & 0.659 & 0.207 & 0.372 & 0.203 & 0.238 & 0.158 & 0.329 & 0.216 \\
\hline Arthritis/Rheumatism & 0.695 & 0.389 & 0.376 & 0.129 & 0.176 & 0.278 & 0.342 & 0.389 \\
\hline Asthma & 0.620 & 0.071 & 0.329 & 0.000 & 1.000 & 0.188 & 0.104 & 0.132 \\
\hline Back problems & 0.568 & 0.275 & 0.594 & 0.881 & 0.235 & 0.354 & 0.347 & 0.999 \\
\hline Bowel disease & 0.236 & 0.075 & 0.143 & 0.089 & 0.147 & 0.059 & 0.265 & 0.037 \\
\hline Cataract & 0.246 & 0.026 & 0.029 & 0.000 & 0.003 & 0.014 & 0.016 & 0.000 \\
\hline Diabetes & 0.309 & 0.206 & 0.015 & 0.052 & 0.021 & 0.108 & 0.081 & 0.000 \\
\hline Emphysema/Bronchitis/COPD & 0.493 & 0.005 & 0.133 & 0.216 & 0.191 & 0.059 & 0.072 & 0.104 \\
\hline Food allergy & 0.258 & 0.214 & 0.283 & 0.000 & 0.336 & 0.086 & 0.203 & 0.162 \\
\hline Heart disease & 0.379 & 0.122 & 0.008 & 0.087 & 0.006 & 0.090 & 0.053 & 0.000 \\
\hline High blood pressure & 0.544 & 0.723 & 0.000 & 0.293 & 0.000 & 1.000 & 0.000 & 0.000 \\
\hline Incontinence & 0.324 & 0.044 & 0.073 & 0.000 & 0.000 & 0.023 & 0.073 & 0.019 \\
\hline Migraine & 0.667 & 0.268 & 0.396 & 0.304 & 0.107 & 0.279 & 0.509 & 0.475 \\
\hline Thyroid condition & 0.135 & 0.109 & 0.124 & 0.000 & 0.044 & 0.075 & 0.247 & 0.000 \\
\hline Ulcers & 0.496 & 0.000 & 0.107 & 0.481 & 0.059 & 0.121 & 0.151 & 0.063 \\
\hline \multirow[t]{3}{*}{ Chronic disease } & \multicolumn{8}{|c|}{$\geq 55$ Years } \\
\hline & \multicolumn{4}{|c|}{ Aboriginal } & \multicolumn{4}{|c|}{ Matched Non-Aboriginal Caucasian } \\
\hline & $\begin{array}{c}\text { Class } 1 \\
(17.6 \%)\end{array}$ & $\begin{array}{c}\text { Class } 2 \\
(51.5 \%)\end{array}$ & $\begin{array}{l}\text { Class } 3 \\
(27.0 \%)\end{array}$ & $\begin{array}{l}\text { Class } 4 \\
(3.9 \%)\end{array}$ & $\begin{array}{c}\text { Class } 1 \\
(9.3 \%)\end{array}$ & $\begin{array}{c}\text { Class } 2 \\
(19.6 \%)\end{array}$ & $\begin{array}{l}\text { Class } 3 \\
(53.0 \%)\end{array}$ & $\begin{array}{c}\text { Class } 4 \\
(18.1 \%)\end{array}$ \\
\hline Anxiety/Mental disorders & 0.301 & 0.084 & 0.121 & 0.285 & 0.258 & 0.058 & 0.059 & 0.395 \\
\hline Arthritis/Rheumatism & 0.934 & 0.574 & 0.651 & 0.000 & 0.909 & 0.434 & 0.683 & 0.624 \\
\hline Asthma & 0.664 & 0.058 & 0.082 & 0.000 & 0.213 & 0.063 & 0.134 & 0.038 \\
\hline Back problems & 0.610 & 0.227 & 0.525 & 0.695 & 0.421 & 0.174 & 0.375 & 0.513 \\
\hline Bowel disease & 0.174 & 0.021 & 0.144 & 0.000 & 0.426 & 0.000 & 0.091 & 0.194 \\
\hline Cataract & 0.139 & 0.212 & 0.102 & 0.640 & 0.388 & 0.165 & 0.128 & 0.000 \\
\hline Diabetes & 0.367 & 0.399 & 0.000 & 0.000 & 0.617 & 1.000 & 0.000 & 0.000 \\
\hline Emphysema/Bronchitis/COPD & 0.524 & 0.085 & 0.007 & 0.839 & 0.412 & 0.004 & 0.108 & 0.000 \\
\hline Food allergy & 0.131 & 0.101 & 0.229 & 0.000 & 0.186 & 0.012 & 0.060 & 0.114 \\
\hline Heart disease & 0.232 & 0.295 & 0.099 & 0.007 & 0.489 & 0.195 & 0.276 & 0.000 \\
\hline High blood pressure & 0.506 & 0.758 & 0.082 & 0.000 & 0.609 & 0.782 & 0.662 & 0.460 \\
\hline Incontinence & 0.223 & 0.090 & 0.053 & 0.349 & 0.265 & 0.037 & 0.097 & 0.039 \\
\hline Migraine & 0.303 & 0.079 & 0.304 & 0.000 & 0.173 & 0.005 & 0.045 & 0.165 \\
\hline Thyroid condition & 0.282 & 0.153 & 0.173 & 0.000 & 0.279 & 0.060 & 0.087 & 0.453 \\
\hline Ulcers & 0.170 & 0.033 & 0.208 & 0.533 & 0.016 & 0.062 & 0.061 & 0.105 \\
\hline
\end{tabular}

Abbreviations: CCHS, Canadian Community Health Survey; COPD, chronic obstructive pulmonary disease.

Note: Bold values represent diseases with item response probabilities of 0.400 or greater.

\section{Older group}

In the four-class model for the older Aboriginal respondents (Table 3), the first class comprised slightly less than one-fifth of the sample (17.6\%) and had high itemresponse probabilities on 5 of the 15 chronic conditions. The second class had high probabilities for arthritis/rheumatism and blood pressure, while the third had high probabilities for arthritis/rheumatism and back problems. The fourth class, which comprised the smallest percentage of members in the group (3.9\%), had high item-response probabilities for four chronic conditions (back problems, cataracts, emphysema and ulcers). Among the non-Aboriginal respondents in the older age group, the first class $(9.3 \%$ ) had seven chronic conditions with high itemresponse probabilities while subsequent classes had fewer conditions with high 
probabilities. However, there were similarities in the disease clusters in both Aboriginal and non-Aboriginal populations.

\section{Discussion}

This is the first nationally representative study to compare the prevalence of multimorbidity and investigate co-occurring chronic diseases patterns in Aboriginal and matched non-Aboriginal Caucasian populations. Our results reveal that the Aboriginal population had higher overall prevalence of multimorbidity as well as higher prevalence for most of the investigated chronic diseases.

We identified a small group of younger Aboriginal respondents in the three-class model (5.8\%) and four-class model (6.0\%) with high prevalence of multiple chronic conditions. A cluster with similar characteristics was not evident among younger non-Aboriginal Caucasian respondents. Other disease clusters identified in the younger age group in both populations had just one or two highly prevalent conditions in the three- and four-class models.

Unlike the younger age group, the chronic disease clusters in the older age group for the three-class and four-class models were frequently comprised of three or more conditions, and there were some similarities in the latent classes identified in the Aboriginal and non-Aboriginal populations. For instance, in the three-class model, arthritis/rheumatism, diabetes and high blood pressure had the highest probabilities of co-occurrence in both populations.

Some of the chronic disease clusters identified in our study were similar to those identified in previous research. A study conducted on a sample of workingage Australians identified six chronic disease clusters. $^{22}$ They found that arthritis, back/neck problems, migraine and other chronic pain conditions tended to co-occur. This is similar to our results: we found that arthritis/rheumatism and back problems tended to co-occur. We also found a disease cluster made up of arthritis/rheumatism, back problems, bowel disease, diabetes, heart disease, high blood pressure, and
emphysema/bronchitis/COPD in the older non-Aboriginal Caucasian population. The Australian study ${ }^{22}$ found similar conditions (i.e. cardiovascular disease, diabetes, fatigue, high blood pressure, high cholesterol, arthritis) in one cluster.

\section{Limitations}

First Nations living on reserve comprise a significant portion of the total Aboriginal population but were not included in this study; therefore the results are representative of only the off-reserve Aboriginal population of Canada. The data are from a cross-sectional survey and therefore provide a snapshot of multimorbidity at one point in time; diseases that cluster may change over time. Although we matched the Aboriginal and non-Aboriginal Caucasian respondents on two important demographic variables (i.e. age and sex), the two populations may still differ in terms of socioeconomic characteristics, which may also be associated with multimorbidity. Residual confounding may therefore account for some of the differences in disease clustering between the two populations. There may be differences in access to health care services between Aboriginal and non-Aboriginal populations, which may result in under-reporting of diagnosed chronic diseases. This underreporting may be more likely to affect the Aboriginal population.

Further, surveys are prone to self-reporting bias due to failure to accurately recall previously diagnosed conditions and the social undesirability of certain health conditions.

Further research could investigate whether individuals within different chronic disease clusters have different patterns of health care utilization, including utilization of emergency, acute, primary, and supportive care. Such findings will be useful in ascertaining the clinical relevance and cost implications of different patterns of multimorbidity.

\section{Conclusion}

Our findings emphasize the dynamics of co-occurring chronic diseases in Aboriginal and non-Aboriginal Caucasian populations in Canada. The Aboriginal population had higher prevalence of multimorbidity than an age-and-sex-matched non-Aboriginal Caucasian population. Although there were some similarities in the diseases that tended to co-occur in the older Aboriginal and non-Aboriginal Caucasian populations, differences existed in the younger age group. Understanding the differences in diseases that are likely to co-occur in different populations can help in developing tailored prevention and management strategies.

We found a small group of the younger Aboriginal respondents who had complex co-occurring chronic diseases. This group in particular may benefit from disease prevention and management programs.

\section{Contributors}

JPK, LML and SS contributed substantially to the conception and design, acquisition, analysis and interpretation of data and the final approval of the version to be published. JPK and LML were responsible for drafting the article or revising it critically for intellectual content.

\section{Acknowledgements}

The authors are indebted to the staff of the Statistics Canada Research Data Centre in Winnipeg, MB, especially Dr. Ian Clara, for technical support.

Although this study has been approved by Statistics Canada as part of data access requirements, the interpretation and conclusions contained herein do not necessarily represent those of Statistics Canada.

JPK has been supported by a fellowship from the Western Regional Training Centre (WRTC) in Health Services Research, University of Manitoba and Manitoba Health Research Council Studentship. LML is supported by a Manitoba Research Chair from the Manitoba Health Research Council.

There were no competing interests. 


\section{References}

1. Van den Akker M, Buntinx F, Metsemakers JF, Roos S, Knottnerus JA. Multimorbidity in general practice: prevalence, incidence, and determinants of co-occurring chronic and recurrent diseases. J Clin Epidemiol. 1998;51:367-75.

2. McGann PE. Comorbidity in heart failure in the elderly. Clin Geriatr Med. 2001;16: 63148 .

3. Patrick L, Knoefel F, Gaskowski P, Rexroth D. Medical comorbidity and rehabilitation efficiency in geriatric inpatients. J Am Geriatr Soc. 2001;49:1471-7.

4. Wolff JL, Starfield B, Anderson G. Prevalence, expenditure, and complications of multiple chronic conditions in elderly. Arch Inter Med. 2002;162:2269-76.

5. Orueta JF, Nuno-Solinis R, Garcia-Alvarez A, Alonso-Moran E. Prevalence of multimorbidity according to the deprivation level among the elderly in the Basque country. BMC Public Health. 2013;13:918.

6. Tucker-Seeley RD, Li Y, Sorensen G, Subramanian SV. Lifecourse socioeconomic circumstances and multimorbidity among older adults. BMC Public Health. 2011;11:313.

7. Mathur R, Hull SA, Badrick E, Robson J. Cardiovascular multimorbidity: the effect of ethnicity on prevalence and risk factor management. Br J Gen Pract. 2011;61:e26270.

8. Shadmi E. Multimorbidity and equity in health. Int J Equity Health. 2013;12:59.

9. Schafer I, von Leitner EC, Schon G, et al. Multimorbidity patterns in the elderly: a new approach of disease clustering identifies complex interrelations between chronic conditions. Plos ONE. 2010;5(12):e15941.

10. Prados-Torres A, Poblador-Plou B, CalderonLarranaga A, et al. Multimorbidity patterns in primary care: Interactions among chronic diseases using factor analysis. Plos ONE. 2012;7(2):e32190.

11. Cornell JE, Pugh JA, Williams JW, et al. Multimorbidity clusters: Clustering binary data from a large administrative medical database. Appl Multivar Res. 2008;12:16382 .
12. Marengoni A, Rizzuto D, Wang HX, Winblad B, Fratiglioni L. Patterns of chronic multimorbidity in the elderly population. J Am Geriatr Soc. 2009;57:225-30.

13. Newcomer SR, Steiner JF, Bayliss EA. Identifying subgroups of complex patients with cluster analysis. Am J Manag Care. 2011;17(8):e324-32.

14. Kaldor J, Clayton D. Latent class analysis in chronic disease epidemiology. Stat Med. 1985;4(3):327-35.

15. Magidson J, Vermunt JK. Latent class models for clustering: a comparison with K-means. Can J Market Res. 2002;20:37-44

16. Deering KN, Lix LM, Bruce S, Young TK. Chronic diseases and risk factors in Canada's northern populations: longitudinal and geographic comparisons. Can J Public Health. 2009;100(1):14-7.

17. Diabetes in Canada: facts and figures from a public health perspective [Internet]. Ottawa (ON): Public Health Agency of Canada; 2011 [cited 2014 Jan 11]. Available at: http:// www.phac-aspc.gc.ca/cd-mc/publications /diabetes-diabete/facts-figures-faits-chiffres -2011/index-eng.php?utm_source $=$ Stake holders\&utm_medium = email_eng\&utm campaign $=$ DiabetesReport 2011

18. Statistics Canada. Canadian Community Health Survey. Detailed information for 2005 (Cycle 3.1) [Internet]. Ottawa (ON): Statistics Canada; 2005 [cited 2013 Dec 30]. Available at: http://www23.statcan.gc.ca/imdb $/$ p2SV.pl?Function $=$ getSurvey\&SurvId $=$ 1630\&InstaId $=22642 \&$ SDDS $=3226$

19. Statistics Canada. Canadian Community Health Survey, Cycle 3.1. Final Questionnaire [Internet]. Ottawa (ON): Statistics Canada; 2005 [cited 2013 Dec 30]. Available at: http://www23.statcan.gc.ca/imdb-bmdi /instrument/3226_Q1_V3-eng.pdf

20. Stuart EA. Matching methods for causal inference: a review and a look forward. Stat Sci. 2010;25(1):1-21.

21. Lanza ST, Collins LM. A new SAS procedure for latent transition analysis: Transitions in dating and sexual risk behaviour. Dev Psychol. 2008;44(2):446-56.
22. Holden L, Scuffham PA, Hilton MF, Muspratt A, Ng SK, Whiteford HA. Patterns of multimorbidity in working Australians. Popul Health Metrics. 2011;9:15.

23. Akaike H. A new look at the statistical model identification. IEEE Trans Autom. 1974;19:716-23.

24. Schwartz G. Estimating the dimension of a model. Ann Statist. 1978; 6:461-4.

25. Lanza ST, Collins LM, Lemmon DR, et al. Proc LCA: a SAS procedure for latent class analysis. Struct Equ Modeling. 2007;14(4): 671-94.

26. PROC LCA \& PROC LTA (Version 1.2.7) [Software]. Penn State: The Methodology Center, PA; 2011 [cited 2013 July 20]. Available at: http://methodology.psu.edu

27. SAS Institute Inc. SAS/STAT user's guide. Cary, NC: SAS Institute Inc; 2004. 